\title{
Do teatro realista ao teatro do real
}

\section{From realistic theater to real theater}

\author{
Andréa da Silva Rabelo \\ Yuri de Andrade Magalhães
}

Andréa da Silva Rabelo

Doutoranda pelo Programa de Pós-Graduação em Artes Cênicas da

Universidade Federal da Bahia (PPGAC/UFBA), atriz e professora

Yuri de Andrade Magalhães

Doutorando pelo Programa de Pós-Graduação em Artes Cênicas da Universidade Federal da Bahia (PPGAC/UFBA), com bolsa Fapesb, e professor

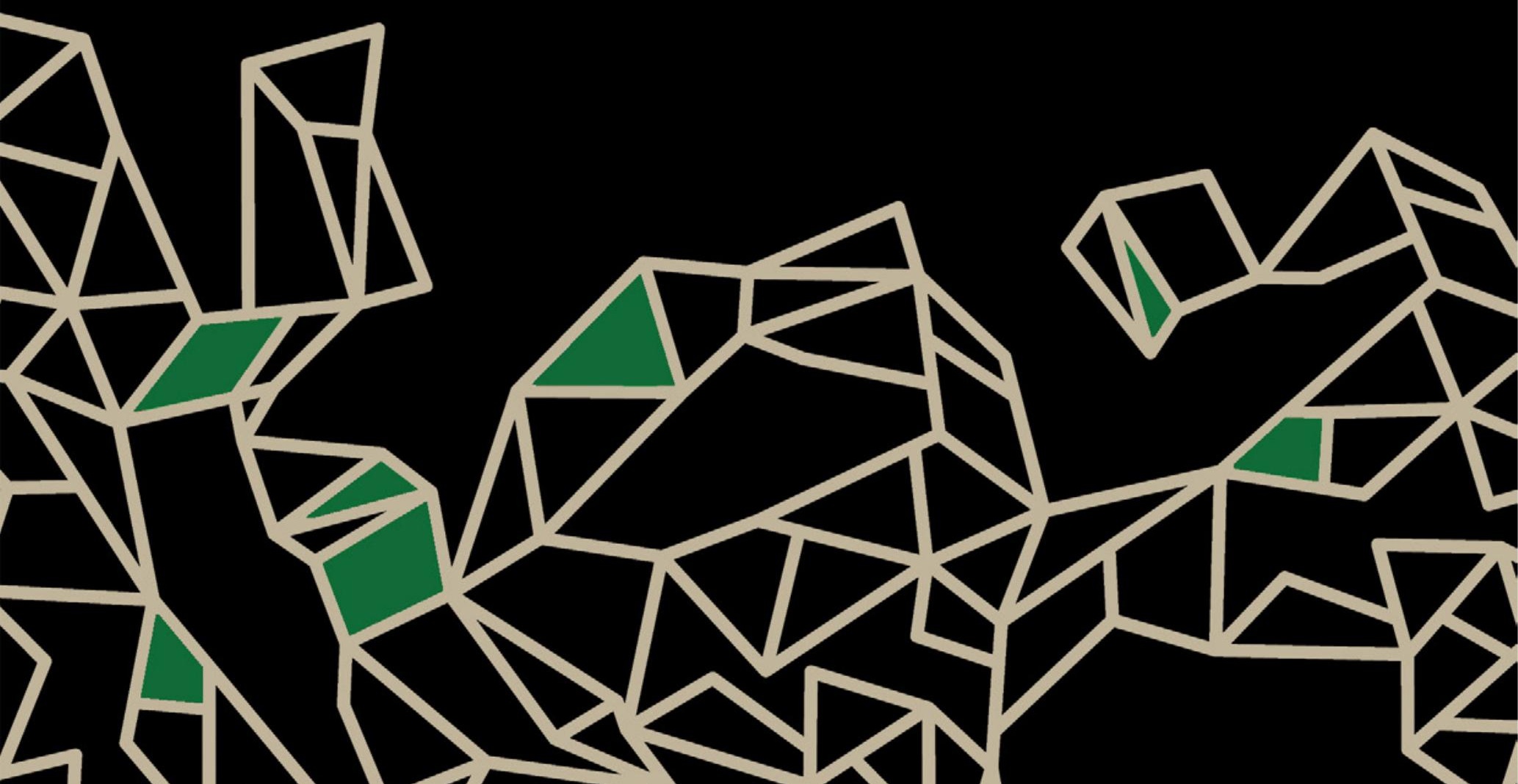




\section{Resumo}

Este artigo busca traçar um panorama e compreender os diversos aspectos que influenciaram o desenvolvimento do teatro realista rumo ao que entendemos hoje por "teatro do real". Surgido no século XIX na França, em oposição ao teatro romântico, o teatro realista estendeu sua influência para vários outros países, incluindo o Brasil. No decorrer dos anos, diversas vanguardas teatrais passam a rejeitar o realismo e o subsequente naturalismo em busca de novas abordagens e experiências que pudessem ser proporcionadas pelo teatro, bem como para experimentar novas formas de relação entre cena e público. Nesse sentido, dialogando com autores pertencentes a diferentes épocas (e contextos), procuramos analisar e compreender como se deu esse percurso entre um teatro que propõe uma realidade cênica em seu aspecto visual e um teatro que propõe uma experiência com o real.

Palavras-chave: Teatro realista, Teatro do real, Realismo, Experiência.

\section{Abstract}

This article analyzes the various aspects that have influenced the development of realistic theater up until what is today understood as "real theater". Arising in the nineteenth century in France and being opposed to romantic theater, realistic theater has extended its influence to several other countries, including Brazil. As the years go by, several theater vanguards refused realism and the subsequent naturalism by searching new approaches and experiences that could be provided by the theater, as well as experience new ways of relationship between scene and audience. By undergoing dialogue with authors from different ages and contexts, we verify how this trajectory took place between a theater that proposes a scenic reality in its visual aspect and a theater that proposes an experience with reality.

Keywords: Realistic theater, Real theater, Realism, Experience.

Em pleno século XIX, Paris presenciava o conflito entre Classicismo e Romantismo. O Classicismo voltava a dominar o palco e a ditar o que deveria ser entendido como "bom senso" na literatura e na cena. Os românticos, por sua vez, rejeitavam veementemente as regras impostas pelo Classicismo, especialmente no que tange à obediência às unidades aristotélicas e à 
delimitação do potencial criativo a aspectos formais. Os classicistas, que viam em Jean Racine um grande mestre, buscavam o verossímil pelo uso das regras. Os românticos, por sua vez, resgatavam William Shakespeare como um exemplo que deveria ser seguido, buscavam como fonte de inspiração a própria natureza e priorizavam a criatividade, o "gênio", em detrimento da "forma", que era tão cara aos classicistas.

O Romantismo, com Victor Hugo, propõe um diálogo mais efetivo com a realidade social, diferentemente dos alemães do movimento Sturm und Drang, do século XVIII. Na contramão da racionalidade burguesa, o herói romântico alemão era movido por motivações como ambição, paixão e vingança. No que se refere à preocupação com a verossimilhança, o autor francês considerava leviano confundir arte com realidade, como queriam alguns românticos influenciados pelas "leis da natureza" na composição poética. Victor Hugo entendia que a verdade da arte não poderia ser vista como "absoluta", pois não é capaz de dar a própria coisa; em outros termos, podemos dizer que na arte não devemos tomar a "metáfora pela coisa."Vejamos a citação do autor a esse respeito:

O Cid fala em versos! Não é natural falar em versos, - Como quer então que ele fale? - Em prosa. - Seja. - Após um instante: - Como, retomará ele se for consequente, o Cid fala em francês! - E então? - A natureza quer que ele fale sua língua, ele não pode falar senão espanhol. Não compreenderemos nada; mas seja ainda. - Creem que isso é tudo? Não é; antes da décima frase castelhana, deve levantar-se e perguntar se este Cid que fala é o verdadeiro Cid, em carne e osso? Com que direito este ator, que se chama Pedro ou Tiago, toma o nome de Cid? Isto é falso. - Não há razão alguma para que não exija em seguida que se substitua essa rampa pelo sol, esses mentirosos bastidores por árvores reais, casas reais. Pois, uma vez nesta via, a lógica nos agarra pelo colarinho, não podemos mais deter-nos. (HUGO, 2002, p. 67-68)

No que se refere ao rigor dos classicistas com as regras aristotélicas na escrita dramática, cabe-nos aqui lembrar de Pierre Corneille e sua obra O Cid. Pertencente ao Neoclassicismo francês, sabemos que o drama foi, em sua época, acusado de atentar contra a verossimilhança, e Roubine (2003) acresce que Corneille foi acusado por Chapelain do "crime" de lesa-aristotelismo. Ainda que $\mathrm{O}$ Cid tenha sido fortemente aclamado pela juventude 
francesa, Corneille foi rechaçado com veemência por seus pares intelectuais da Sociedade dos Cinco Autores.

Corneille não se preocupou, em $\mathrm{O}$ Cid, com o fato de um personagem (na trama) viajar e retornar dias ou meses depois; não se importou de mesclar a linguagem ornamentada da tragédia com a linguagem vulgar da comédia; não se privou de mesclar personagens cômicos e trágicos; não abriu mão de utilizar diversas ações secundárias em relação à ação principal; não se inibiu de situar as cenas em diversos lugares e de lançar mão de todo tipo de artifício e criatividade para manter seu público empolgado e atento ao desenlace da trama - contrariando completamente o Classicismo e suas regras. No século XIX, o Romantismo combate frontalmente o Classicismo e, na contramão de ambos, o Realismo surge ainda pela metade do mesmo século, conforme descreve Magalhães (2015, p. 5):

Na contramão do Romantismo, surge o movimento realista na literatura e nas artes que busca, de fato, reproduzir a realidade (quase fotograficamente), bem como expor as engrenagens das conjunturas sociais, culturais e filosóficas inseridas. O Realismo é descendente do drama social experimentado por Émile Augier e Alexandre Dumas Filho, que tem como principal obra a Dama das Camélias. O drama social, porém,tem objetivo didático e moralizante, assim como o Realismo possui frequentemente caráter de denúncia social, surge então o movimento naturalista.

Podemos observar que, a partir do Realismo, o teatro passa a se preocupar mais enfaticamente com a realidade objetiva que se nos apresenta em nossa vida cotidiana. A dramaturgia realista abre mão dos heróis trágicos que povoam a dramaturgia da Antiguidade, retomados no Classicismo e Neoclassicismo durante o Renascimento; já não possui o caráter teologizante do drama medieval; nem a sátira e o escárnio da Commedia dell'Arte; nem se concentra mais nos sofrimentos de um jovem chamado Werther, como fez Goethe em seu romance - tão caro ao movimento Sturm und Drang -; e já não enfatiza o poderoso protagonismo de personagens de grande carga histórica e nacional, como um Ricardo III ou uma Maria Stuart. No Realismo os personagens são pessoas comuns, que exercem profissões como médico, advogado, tecelão, entre outros. 
O Naturalismo radicaliza a tentativa de reprodução fotográfica da realidade no palco. Enquanto o Realismo recorre a signos arbitrários, facilmente assimilados pela plateia, o Naturalismo opta por colocar objetos reais em cena e propõe a uma abordagem mais "científica" da realidade. Influenciado pelas ideias de Émile Zola e pelas palestras de Hippolyte Taine, André Antoine fundou seu Théâtre Libre em 1887 e passou a experimentar o Naturalismo.

Ao longo do século $\mathrm{XX}$ ocorreram diversas modificações na relação entre cena e público. Essas inovações não são apenas cênicas, mas também dramatúrgicas. Peter Szondi (2001) aponta uma "crise do drama", que ele situa no período de 1880 a 1950, partindo da análise de dramaturgos que se destacaram nesse intervalo de tempo. Ibsen, Maeterlinck, Hauptmann e Tchékhov são considerados os principais expoentes dessa crise por se distanciarem daquilo que, a partir de Hegel, passou a ser entendido como drama.

Dentre os dramaturgos mencionados por Szondi (lbid.), tomemos os exemplos de Ibsen e de Tchékhov. Em Ibsen, a exemplo de sua Casa de bonecas, nos deparamos com uma ação aparentemente estática, que parece não progredir e não se intensificar, comprometendo significativamente a dinâmica do conflito. A variação qualitativa, a reviravolta, se dá quando algo ocorrido no passado é trazido à tona, como o empréstimo que a personagem Nora fez. Conforme aponta Szondi (Ibid.), em Tchékhov também nos deparamos como uma ação aparentemente estática em $O$ jardim das cerejeiras. Nessa obra, as personagens agem sob o signo da renúncia, simplesmente aceitam que a venda do terreno é inevitável e passam toda a trama envolvidas em uma atmosfera melancólica e nostálgica, que se reflete nos diálogos a respeito do jardim.

A solução para essa crise, segundo Szondi (Ibid.), seria o "drama épico" proposto por Brecht - o autor chega ao ponto de defender que dramaturgos como Ibsen, Tchékhov, Maeterlinck e Hauptmann seriam personagens de uma espécie de processo evolutivo que chegaria a seu estágio máximo em Brecht. Esse entendimento de Szondi é rebatido pelo francês Jean-Pierre Sarrazac (2012) que, por sua vez, esclarece que a crise do drama, irrompida em 1880, consiste numa resposta às novas relações que o homem mantém com o mundo e a sociedade, instaladas sob o signo da "separação". 
Que separação seria essa? Quando se fala do século XX, diversas separações são feitas entre o homem psicológico, o econômico, o moral, o metafísico etc. Esse homem "massificado" é também um homem "separado" - do corpo social, de Deus, das forças invisíveis e simbólicas, de si mesmo -, dividido, fragmentado e despedaçado, esclarece Sarrazac (Ibid.).

Sarrazac (Ibid.) discorda de Szondi quando este se refere à forma épica proposta por Brecht como uma solução para essa crise. Para o teórico francês, a crise não está necessariamente atrelada a uma necessidade de "solução", pois podemos falar de uma crise "sem fim". Concordando com Sarrazac, trata-se de uma crise permanente, sem solução, sem horizonte preestabelecido, que possui imprevisíveis linhas de fuga.

O "textocentrismo" é um aspecto que também entrou em crise com o surgimento da encenação, a qual confere maior autonomia à figura do diretor, que passa a ser preferencialmente denominado de "encenador." Na contemporaneidade, a mimese assume efetivamente seu lugar enquanto poiesis espetacular. Para Ramos (2015), pensar a mimese como instrumento relevante para operar a cena contemporânea é também desafiar a tradição modernista, que definiu tal conceito como "ultrapassado" ou como uma "arte menor". Ao mesmo tempo, Ramos (Ibid.) esclarece que a mimese é incompatível com o projeto das vanguardas históricas do início do século XX, que deflagrou diversas possibilidades para as artes, em sua maioria antimiméticas - e é esse sentimento antimimético que se confundirá com uma perspectiva antiteatral, influenciando decisivamente o teatro praticado ao longo do século $X X$. Isso resulta, conforme Ramos (Ibid.), em uma "crise da representação", à qual o teatro do real, tão caro à contemporaneidade, está diretamente relacionado.

O tratamento hierárquico entre texto e encenação já é dado por Aristóteles (1966) em sua Poética quando, ao discorrer acerca dos seis elementos da tragédia, coloca o opsis (espetáculo) como o menos importante para suscitar a catarse, que poderia ser perfeitamente alcançada com a leitura. Nessa perspectiva, para Ramos (Op. cit., p. 23), pensar a teatralidade contemporaneamente:

requer diferenciar nela o que está afeito ao dramático, funcionando nas correias da transmissão narrativa do tempo e espaço cênicos e confundindo com a dita carpintaria teatral, do que é a expressão da condição 
intrínseca do espetáculo, de sua materialidade e tridimensionalidade, como superfície que se dá a ver, e, tempo-espacialmente indissociável do aqui e agora, aproximando-se da pintura e da escultura no aspecto contemplativo.

Atualmente, cena e dramaturgia são entidades autônomas, já não se encontram em uma relação hierárquica. Admite-se, inclusive, a possibilidade de a dramaturgia surgir da própria cena, do próprio processo, concordando com o apontamento de Ramos (Ibid.) de que a ideia de uma "dramaturgia da cena" já pressupõe uma inversão dessa perspectiva habitual, colocando a cena como elemento primário e a dramaturgia como elemento secundário. Podemos tomar isso como uma clara diferença entre o teatro realista e o teatro do real: neste último podemos concordar com a ideia de que a cena tem sua própria textualidade, que suplanta seus antecedentes literários.

Leonor Arfuch (2010, p. 28) contextualiza, no horizonte da modernidade, que "é no século XVIII, com a consolidação do capitalismo e da ordem burguesa, que começa a se afirmar a subjetividade moderna". Esse cenário possibilita outro aspecto que justifica a dissociação do opsis em detrimento do enredo na cena contemporânea, além de ressaltar diferenças entre o teatro do real e o teatro realista: é nesse momento de valorização das subjetividades que os artistas começam a tomar para si os discursos sobre a própria arte. Assim surgem encenadores, como Stanislavski ou Grotowski, que produzem reflexões sobre os processos criativos, pensam sobre a arte que fazem e alimentam o imaginário dos artistas cênicos posteriores a eles. Até esse momento, o pensamento sobre a arte partia majoritariamente de filósofos e teóricos, a exemplo de Platão, Aristóteles e Boileau - indivíduos que não se dedicavam à vivência prática do teatro, mas eram comentadores de um ponto de vista exterior à sua criação. Esse pressuposto faz toda a diferença em relação à arte criada desde então.

Neste sentido, o artista se interessa em se apropriar do seu discurso na cena, como também em produzir análises críticas sobre seus processos de encenação, em vez de ser apenas porta-voz do discurso de um dramaturgo ou mesmo de se submeter a esse soberano nas tradições clássica, romântica e realista. Cada vez mais a individualidade artística passa a ter maior importância na cena, e mais enfaticamente a vivência do artista e a 
experiência proporcionada pelo espetáculo, produzindo discursos como os de Antonin Artaud (1984).

A crise do textocentrismo - e a consequente valorização do espetáculo - gerou efeitos como a maior codificação da cena em contraposição à ideia de "quarta parede", produzindo um teatro em que era visível o artifício, de uma visualidade poética, metafórica. Logo nos primeiros anos deste século, segundo o pesquisador espanhol José Antonio Sánchez (2007, p. 4, tradução nossa),

os escritores sentiram a impotência das palavras para representar uma realidade que não se deixava conceituar e que lhes assaltava (Hofmannsthal), ou retrocederam a uma construção visionária do real que obrigava à destruição da sintaxe e dos esquemas de representação; o expressionismo fez então do solipsismo um programa artístico. ${ }^{1}$

Observamos assim uma construção que se distancia da realidade na medida em que não a consegue expressar por palavras, buscando na prática solipsista a forma mais possível de ordenar sua visão do mundo. Mais adiante, a pós-modernidade traz novamente uma dissociação entre o real e a realidade. Em seu artigo "Prácticas de lo real", Sánchez (Ibid.) traz o caso do teatro histórico de Ariane Mnouchkine. O autor observa que no espetáculo Norodon Sihanouk, rey de Camboya (1985), realizado durante o exílio do rei cambojano da França, apesar da conexão histórico-social e da referência ao real, havia um excesso de teatralidade, uma preocupação com a imagem, a utilização de técnicas diversas de representação, elementos poéticos e fantásticos que distanciavam do concreto, criavam um relato espetacularizado em detrimento da realidade da história.

Já na década de 1990 surge o desejo de levar o real de volta à cena. O termo "teatros do real" foi cunhado pela professora francesa Maryvonne Saison: "segundo a autora, em determinadas experiências do teatro contemporâneo priorizava-se a concretização material da presença do ator, do espaço, do objeto e da situação, em oposição à relação mimética, abstrata, da representação com aquilo que representa" (FERNANDES, 2013, p. 4).

1 No original: "los escritores sintieron la impotencia de las palabras para representar una realidad que no se dejaba conceptuar y que las asaltaba (Hofmannsthal) o se retrajeran a una construcción visionaria de lo real que obligaba a la destrucción de la sintaxis y de los esquemas de representación; el expresionismo hizo entonces del solipsismo un programa artístico". 
Enquanto os teatros realista e naturalista se caracterizavam pela representação da realidade, numa tentativa de reproduzi-la fotograficamente - traduzida na expressão da "fatia de vida" transposta para o palco -, os chamados "teatros do real", tendência da contemporaneidade, se distanciam da noção de representação, afrontando-a com a irrupção do real na cena. O teatro documental, autoficcional, autobiográfico, como também a performance são formas que dialogam com os movimentos desenvolvidos em outras linguagens artísticas, nas quais o real é convocado não apenas como reprodução, mas como algo presente na cena, a coisa em si. O real então se caracterizaria, entre outras coisas, pelo compartilhamento da experiência entre artista e público.

André Carreira (2011) chama de "tempo sem segredos" este em que a noção de privacidade está completamente abalada diante da superexposição do indivíduo nas redes sociais ou na TV. Os meios de comunicação de massa e a internet, como ferramentas capitalistas que são, estimulam os desejos dos consumidores, vendendo fama através da exposição cada vez mais invasiva da intimidade e da espetacularização da vida. Esse real que se introduz na obra de arte é resposta a um tempo em que se diluem as fronteiras entre público e privado, em que o coletivo se faz a partir da exposição das subjetividades, ora de modo artificial - nos realities e sua verdade fabricada -, ora nas artes experimentais, especialmente nas artes cênicas (aqui discutidas), em que o público é convocado a participar da experiência artística.

Seria uma demanda do artista confrontar essa realidade dispersa e repleta de informações, muitas vezes inverossímeis ou desconexas? Carreira faz a seguinte afirmação:

Podemos pensar esses movimentos como respostas determinadas por uma urgência. Assim se manifestaram artistas que não viram outro caminho senão o de levar sua arte ao estado de confissão, no meio de uma cultura que parece ter destruído toda a possibilidade de privacidade, ainda que isso soe como paradoxal. (Ibid., p. 335)

Ao passo que autoexposição midiática ou virtual cria personagens que não necessariamente correspondem à realidade daquele indivíduo, como uma espécie de "avatar," o desejo do criador e do artista parece endereçar-se a outro ponto. Cada vez mais alguns atores/performers distanciam-se 
da noção de personagem e, no palco, a plateia vê o artista, o sujeito que se desnuda e se expõe; ele busca estar verdadeiramente presente, o que os torna (artista e público) íntimos e cúmplices. O público, como testemunha do acontecimento, é um elemento mobilizador do ator/performer, da mesma forma que aquele também é mobilizado por este. Nesse sentido, Carreira (Ibid., p. 339) relata que "aquilo que ocorre na cena sempre compromete o ator como sujeito vivente, e o público tem consciência que sua presença também mobiliza os atores como partícipes da cerimônia espetacular".

Carreira (Ibid.) compreende que há uma potência transformadora nessa presente invasão do real sobre a cena, visto que a tentativa de contato com o real serve como contraponto à espetacularização da realidade. O pesquisador afirma que "a perda de lugares políticos de referência deu impulso a um teatro no qual prepondera a necessidade de autoexpressão, como forma política" (Ibid., p. 334). O teatro, que havia tantas vezes buscado o distanciamento, neste momento expressa uma preocupação em afetar, tentar o contato, numa tentativa de materializar-se através da experiência - e daí promover uma ação efetivamente transformadora.

Fazendo-se, assim, [o teatro] herdeiro de experiências nas quais os limites entre o pessoal e o ficcional estão apagados, esfumados em uma névoa produzida pela aura do artista como principal elemento vinculante da experiência estético política; a cena do pessoal, do autobiográfico, propõe o extremo da intimidade como radicalidade cênica. (Ibid., p. 343)

Ao observar a produção cênica atual, percebemos diversos grupos e companhias teatrais brasileiras que se utilizam com maior ou menor intensidade das tessituras do real na cena. A Cia. Hiato (SP), por exemplo, vem trabalhando elementos biográficos em suas produções, como no espetáculo Ficção, constituído de solos dos atores e atrizes que fazem parte da companhia. $\mathrm{O}$ diretor e dramaturgo Leonardo Moreira partiu de relatos biográficos da vida de cada um dos atores para tecer uma dramaturgia cênica onde se confundem e se entrelaçam vida e ficção. Nas palavras do próprio Moreira, em vez de "colocar a realidade em cena, a gente se perguntou se é possível fugir da ficção na vida" (SOTERÓPOLIS..., 2013)², ficcionalizando as histórias e criando

2 Entrevista cedida ao programa Soterópolis. 
uma dramaturgia da vida. Na apreciação do espetáculo, nota-se a intervenção dramatúrgica feita sobre essas biografias, de forma que se cria um efeito ficcional. "Por que a gente precisa da ficção?,' se indaga Moreira (Ibid.), refletindo sobre o quão intrigante já é a própria vida.

Num dos solos de Ficção, o ator Thiago Amaral não apenas problematiza questões de sua vida, abordando as dificuldades de suas relações paternas, como leva à cena o seu próprio pai. Também a irmã da atriz Aline Filócomo faz uma participação no espetáculo. Esses dois momentos extremos de irrupção do real na cena geram grande impacto para a plateia, que se encontrava confortável nos limites da dúvida. Nesse caso, há uma confrontação com o real que coloca o público definitivamente como testemunha daquele acontecimento. Na visão de José Sánchez, uma das vertentes dos teatros do real "acontece quando a realidade bruta irrompe no tecido ficcional para seccioná-lo, desestabilizá-lo e abrir brechas a diversos tipos de manifestação performativa" (SANCHEZ apud FERNANDES, Op. cit., p. 11). A ficção que o próprio diretor afirma ter criado é rasurada pela presença dos parentes dos atores, que se expõem revelando intimidades de suas relações.

Nos espetáculos da Cia. Hiato, a representação mimética é posta de lado a despeito da materialidade da presença dos atores e das situações que vivem no palco. Estes olham diretamente para os espectadores, que são agora seus interlocutores, e falam para e com eles, num diálogo que ali se estabelece. O tom de voz, raramente impostado, sugere o de alguém que se confessa a um amigo, criando uma proximidade outrora impensada numa construção mimética.

Esse exemplo revela um movimento, cada vez mais frequente na cena contemporânea, de aproximação com o real, uma aparente necessidade de confrontar a representação, o que Fernandes (Ibid., p. 4) considera não como uma tentativa de investigação da linguagem, mas como um desejo de "testemunhar a necessidade de abertura do teatro à alteridade, ao mundo e à história, em detrimento do fechamento da representação, predominante na década de 1980". Essas experiências artísticas parecem expor uma busca do artista por identificar sua produção com o contexto social em que está circunscrito. "O que de mim eu também vou expor?" (METRÓPOLIS..., 2016)

3 Entrevista ao programa Metrópolis sobre o espetáculo Amadores. 
pergunta-se Maria Amélia Farah, outra atriz da Cia. Hiato. Desse modo, concluímos que o teatro não se tem permitido resistir sem um engajamento flagrante e radical com a realidade, e sua plateia também está convocada a fazer parte disso.

\section{Referências bibliográficas}

ARFUCH, L. O espaço biográfico: dilemas da subjetividade contemporânea. Rio de Janeiro: Eduerj, 2010.

ARISTÓTELES. Poética. Tradução: Eudoro de Souza. Porto Alegre: Globo, 1966.

ARTAUD, A. O teatro e seu duplo. Tradução: Teixeira Coelho. São Paulo: Max Limonad, 1984.

CARREIRA, A. A intimidade e a busca de encontros reais no teatro. Revista Brasileira de Estudos da Presença, Porto Alegre, v. 1, n. 2, p. 331-345, jul./dez. 2011. DOI: 10.1590/2237-266022015.

FERNANDES, S. Experiências do real no teatro. Sala Preta, São Paulo, v. 13, n. 2, p. 3-13, 2013. DOI: 10.11606/issn.2238-3867.v13i2p3-13.

HUGO, V. Do grotesco e do sublime: tradução do "Prefácio de Cromwell." Tradução: Célia Berretini. São Paulo: Perspectiva, 2002.

MAGALHÃES, Y. A. A conflitante relação entre teatro e realidade. In: JORNADA LATINO-AMERICANA DE ESTUDOS TEATRAIS, 8., 2015, Blumenau. Anais [...]. Blumenau: Furb, 2015. p. 421-430.

METRÓPOLIS: "Amadores." [S. I.: s. n.], 2016. 1 vídeo (4 min). Publicado pelo canal Metrópolis. Disponível em: https://bit.ly/36hf7uZ. Acesso em: 26 mar. 2019.

RAMOS, L. F. Mimesis performativa: a margem de invenção possível. São Paulo: Annablume, 2015.

ROUBINE, J.-J. Introdução às grandes teorias do teatro. Tradução: André Telles.

Rio de Janeiro: Jorge Zahar Editor, 2003.

SÁNCHEZ, J. A. Prácticas de lo real. In: SÁNCHEZ, J. A. Prácticas de lo real em

la escena contemporánea. Madrid: Visor Libros, 2007. p. 1-7. Disponível em: https://bit.ly/2tN2zyh. Acesso em: 23 jan. 2020.

SARRAZAC, J.-P. (org.). Léxico do drama moderno e contemporâneo. São Paulo: Cosac Naify, 2012.

SOTERÓPOLIS: Hiato. [S. I.: s. n.], 2013. 1 vídeo (5 min). Publicado pelo canal

Prog Soterópolis. Disponível em: https://bit.ly/2sQVoVo. Acesso em: 26 mar. 2019. SZONDI, P. Teoria do drama moderno (1880-1950). São Paulo: Cosac \& Naify, 2001.

Recebido em 26/03/2019

Aprovado em 18/10/2019

Publicado em 09/03/2020 